\title{
Theoretical background of innovation in services in small and medium-sized enterprises: literature mapping
}

\author{
Saymon Ricardo de Oliveira Sousa ${ }^{1,3^{*}}$ (D), Wesley Vieira da Silva ${ }^{1}$, Claudimar Pereira da Veiga ${ }^{2}$ and
} Roselaine Ruviaro Zanini ${ }^{1}$ (D)

\author{
* Correspondence: saymon.ricardo. \\ sousa@gmail.com; https://orcid. \\ org/0000-0002-1824-2484 \\ ${ }^{1}$ Statistics Department, Federal \\ University of Santa Maria - UFSM, \\ Building, 13, Office $1205 \mathrm{C}-\mathrm{CCNE}$, \\ Roraima Ave, 1000, Santa Maria, RS, \\ Brazil \\ ${ }^{3}$ Post-Graduation Program of \\ Production Engineering, Federal \\ University of Santa Maria, UFSM, \\ Roraima Ave, 1000, Santa Maria, RS \\ 97105-100, Brazil \\ Full list of author information is \\ available at the end of the article
}

\begin{abstract}
The aim of this study was to map the innovation of services in small and mediumsized enterprises, as reported on the Web of Science and SCOPUS databases, using a structured review, involving 121 papers published between 1946 and 2019. There has been an increase in the number of studies in recent years, covering 23 countries on six continents, with the UK representing $48.78 \%$ of the studies. Patterns in the use of methods applied in research were identified, as well as a conceptual structure of the field. The main areas of science were finance, marketing, energy, and green engineering. The study makes an original contribution to the literature, highlighting the interest in the expansion of knowledge among the academic community, in addition to enabling a deeper analysis of the relation between the evaluated constructs.
\end{abstract}

Keywords: Innovation in services, Small and medium-sized enterprises, Literature mapping, Systematic literature review

\section{Highlights}

- In recent years, efforts have been expended to create a theory of innovation in services.

- The service innovation follows a similar logic in relation to innovations found in the literature on physical properties.

- Quantitative approaches were the most used by researchers in their investigations into the processes of service innovation in SMEs.

- The results related to investigating the relationship between innovation processes in services and improvements in organizational performance.

- Out identified patterns with the formation of three clusters: strategic pillars, adaptation strategies, and the results strategy. 


\section{Introduction}

The management system of organizations is constantly undergoing challenges, either because of globalization, increasingly demanding consumers, or the need to remain a leader in the market. This encourages companies to reinvent products or services, whether in terms of the development of a new product, in technological innovation and services, or in the modification of existing products (Mompo and Redoli, 2009; Gunday, Ulusoy, Kilic, \& Alpkan, L., 2011; Slack, Brandon-Jones, \& Jhonston, 2015).

The consulted literature on innovation reveals a discussion of the factors that lead companies to adopt behaviors that increase access to the generation of ideas and to contacts, along with the external factors that contribute to the development process (Etzkowitz \& Leydesdorff, 1995; Etzkowitz \& Leydesdorff, 2000; Den Hertog, Van der Aa, \& De Jong, 2010; Blommerde \& Lynch, 2014).

In this sense, companies seek improvements in their processes, adherence to product quality, greater flexibility in services, as well as a reduction in costs associated with the need to innovate. All this occurs in the economic scenario of the contemporary world, in which changes are so rapid changes that no delay in decision-making can be accommodated (Porto, 2013; Sereia, Stal, \& Câmara, 2015; Lopes, Santos, Silva, \& Martins, 2018).

In the literature, it is possible to identify several reasons for carrying out a systematic literature review (SLR). Okoli and Schabram 2010 offer six such reasons: (a) to answer specific research questions; (b) to analyze the specific development of research; (c) to evaluate the use of methodological approaches; (d) to evaluate the use of theoretical models; (e) to develop a method; and (f) to offer suggestions and recommendations for future work.

SLR development enables the identification, mapping, and analysis of relevant research on a specific topic (Tranfield, Denyer, \& Smart, 2003; Biolchini, Mian, Natali, \& Travassos, 2005; Kitchenham \& Charters, 2007; Kitchenham et al., 2009; Vanz \& Stumpf, 2010). The execution of an SLR in the field of service innovation in small and medium-sized enterprises (SMEs) should make use of a model based on the content analysis of Bardin (2011), as well as follow the direction taken in the research protocol described in the works of Tranfield, Denyer, and Smart (2003), Luft and Shields (2003), and Almeida Biolchini, Mian, Natali, Conte, and Travassos (2007), with the aim of bringing methodological rigor to the review.

Considering the above, this research aims at mapping the literature on innovation in services with use of an SLR, based on studies on SMEs included on the Web of Science and SCOPUS journals databases, in order to extent scientific knowledge in this area. This study is built around the following research question: what is the current state of the art of research on the innovation of services performed in SMEs? In addition, secondary questions are elaborated to support this study development as follows:

- What is the annual frequency of publications?

- Which journals include research on service innovation in SMEs?

- Which countries develop more research on the subject?

- What are the main research institutions?

- What are the most cited studies in the analyzed research corpus?

- Which authors are most cited in the studies?

- Which terms are more recurrent? 
- What are the research standards of the studies (approaches, tools, and/or methodologies) being used to evaluate service innovation in SMEs?

This study makes an original contribution to literature because it jointly addresses these themes via theoretical mapping. In addition, the innovative characteristic of this work, when related to similar research, is based on the fact that no thematic mapping or SLR is located in the indexing of the Web of Science and SCOPUS databases. This approach is related to the development process of the theme, requiring further development and in turn justifying the importance of its elaboration. Thus, the work aims to fill this literature gap through a mapping and a structured review approach, which is useful for evaluating the process of innovation in services in the context of SMEs, as well as the generation of scientific and academic knowledge.

The work is structured into five sections, which can be summarized as follows: the first introduces the study; the second presents the theoretical background; the third presents the methodological procedures adopted in the research which guided the development of the SLR and the computational resources used; the fourth presents and discusses the obtained results; and the fifth reports on the conclusions of the study and suggestions for future studies, as well as acknowledgements and references used in the construction of the research.

\section{Theoretical background}

Small and medium-sized enterprises play an essential role in the economic development of a country, containing little empirical evidence on the process of innovation in services, despite their contribution to a wide range of jobs and, to the increase of the gross domestic product, mainly of countries characterized as emerging (Halme, Lindeman, \& Linna, 2012; Hall, Matos, Sheehan, \& Silvestre, 2012; Halme, Kourula, Lindeman, Kallio, Lima-Toivanen, \& Korsunova, 2016).

Authors such as Mbugua et al. (2013) and Meressa (2020) highlight that the growth of micro and small companies is directly linked to the sustainable development of underdeveloped economies. As stated by Meressa (2020), many researches sought to identify the variables that are widely used as determining factors in the growth process of companies. The results of these surveys show different impacts in relation to the various growth factors, such as location, motivation, implementation of technologies, among others.

The effect of the size of companies on innovation has established relevance in recent years, and several studies have sought to examine this relationship, as stated by Prajogo and McDermott (2014). These authors examined this relationship, taking as an essential measure the question of whether the determinants of innovation performance are different between SMEs and large companies. Similarly, the organizational factors and capabilities that have proven to be effective in creating innovation in large companies are also effective in small and medium-sized companies.

Generally, small businesses are inherently affected not only in terms of acquired resources, capacities or skills, but also in the ability to generate those resources through learning economies of scale. Moreover, these resource limitations, in most cases, are associated with trivial management structures, resulting in inefficiency in recognizing market opportunities, low identification of new technologies, and risk aversion, negatively impacting innovation (Bianchi et al., 2010). 
The use of an informal strategic structure is one of the elements punctuated by Charles, Ojera, and David (2015) that direct about $75 \%$ of small companies around the world collapse operationally in the first 5 years of presence in the market. In another line of considerations, the authors state that small companies are fundamental in social issues, whether in the form of job creation or the search for income equality.

The classification of the size of the companies, whether micro, small, medium, or large, have indexes or indicators that are not yet standardized, in which companies, universities, development agencies, institutes, and researchers use classification models according to the research objectives (Martins, Leone, \& Guerra, 2016). Several researchers consider that one of the significant obstacles in studies on SMEs lies in the fact that there is heterogeneity between them. This diversity would partially clarify the complexity in proposing new theories and adequate results (Leone \& Guerra, 2011). SMEs have always been present on the national and international scene. However, the dissemination of the importance of these companies only became more prominent with the study by Staley and Morse (1958) and later, with the reflections of Schumpeter (1961).

For a long time, the state of the art of innovation, its application, and the relationship with different areas of knowledge have been rather segmented; however, in the last decade, there have been growing advances in the field of organizational management (Tidd, 2001; Quadros et al., 2001; Lindegaard, 2010; Lopes et al., 2018).

Innovation in services, products, or processes consists of developing improvements, new concepts, and new technologies aimed at differentiation in the markets and, consequently, competitive advantage for companies (Bettencourt, Brown, \& Sirianni, 2013; Thakur \& Hale, 2013; Carlborg, Kindström, \& Kowalkowski, 2014). The concept of innovation in services is the insertion of new ideas focused on minimizing or eliminating problems, without necessarily offering something tangible, with a view to increasing benefits for customers (Gallouj et al., 2016; Pikkemaat \& Zehrer, 2016).

When investigating the management practices that promote innovative culture in SMEs, Mambrini et al. (2011) showed that innovation is based on ideas from both internal and external sources, involving the necessary synchronism of five components that promote innovation in organizations: strategy and market positioning, structure and internal organizational environment, technology management, people management, and partnership management.

To carry out the innovation process as an organizational strategy, it is important to understand that innovation is a complex task because it occurs at different levels for different purposes and is contingent on the availability of resources. The search for innovations in different sectors starts from new definitions that have expanded their scope and concept over time, as well as describing social innovations, innovations in services, and innovations in public sector, among others, since the process of developing and combining ideas occurs in all human environments (Antúnez-de-Mayolo, 2012; Brandão \& Bruno-Faria, 2013).

In France, Fixari and Pallez (2016) found that efficiency in the management of territorial innovation systems and their effect on economic development is still poor. The functioning of the French system requires management mechanisms with a strategic vision at the collective level, applied to public policies aimed at formulating strategies. 
In Brazil, Oura, Zilber, and Lopes (2016) found that the export performance of SMEs receives a greater impact from international experience than innovation capacity. For Li, Strange, Ning, and Sutherland (2016), in Chinese provinces, foreign direct investment has a positive effect on innovation performance, when associated with absorption capacity, presence abroad, and the intensity of market competition.

Innovation is a priority in developed countries whose strategy for growth and competitiveness is to be differentiated in the research and development of new technologies. The innovation culture of a country or region depends on the articulation of the main innovation actors, government, formal innovation environments, development agencies, companies, and teaching and research institutions, which have different but collaborative roles (Fusco, Coneglian, \& Mucheroni, 2017).

There is a consensus in the academic community that the innovative potential of a company, region, or country can be boosted when partnerships are established among companies, educational institutions, and government (Etzkowitz \& Leydesdorff, 2000; Ivanova \& Leydesdorff, 2014). Such a consensus converges with the triple helix approach, proposed by Etzkowitz and Laydesdorff (1995), which holds that innovation develops in a context of interaction among three spheres of relevant importance for the development of countries, universities, governments, and companies. The effect of interaction among markets has contributed to the development of a country's innovative potential, mainly because it provides the space for sharing knowledge (Etzkowitz \& Leydesdorff, 1995; Etzkowitz \& Leydesdorff, 2000; Ivanova \& Leydesdorff, 2014).

\section{Research methodology}

The construction of the SLR research protocol and its generated results help to evaluate whether or not the studies on the relationship between innovation in services and SMEs present important evidence for decision makers with regard to cognitive biases. This strategy was defined as the result of extracting works that effectively analyze the topic in question, allowing us to measure production rates and the dissemination and development of the knowledge area (Glänzel, 2007; Vinkler, 2010).

The research protocol has been defined as follows: (i) identification of theoretical gaps; (ii) detailed synthesis of the general characteristics of the corpus; (iii) searching on databases based on inclusion and exclusion criteria; (iv) removing duplicate papers; (v) full reading of the papers, in order to analyze the adherence of studies to the research questions and the theme defined ex ante; and (vi) detailed analysis of the characteristics of the research corpus.

The SLR was performed according to the research protocols of Tranfield, Denyer, and Smart (2003), Kitchenham et al. (2009), Biolchini et al. (2005), and Okoli and Schabram (2010), based on research questions defined in the introduction. Note that it is not the purpose of this research to present details of the stages of the process for the construction of the SLR, but to apply it as a methodological tool.

The choice of journal databases, i.e., Web of Science and SCOPUS, is justified because they incorporate other databases such as Science Citation Index Expanded, Social Sciences Citation, Arts \& Humanities Citation Index, Conference Proceedings Citation Index (Science), Conference Proceedings Citation Index, Social Science \& Humanities, Emerging Sources Citation Index, Current Contents Connect, Derwent Innovations IndexSM, KCI, Russian Science Citation Index, SciELO Citation Index, Cambridge 
University Press, Elsevier, Springer, Wiley-Blackwell, Nature Publishing Group, Taylor\&Francis Group, SAGE, Wolters Kluewer, Emerald, Oxford University Press, Cambridge University Press, Oxford University Press, Inder Science Publishers, Bentham Science, and IEEE Xplore.

The following constructs were used to select the works: "service innovation," "small and medium enterprise," and "small and medium-sized enterprises" (as well as related terms). The constructs generated the following query string search on the Web of Science and SCOPUS databases, respectively: TS=("service innovation" AND ("SME" OR "small and medium enterprise" OR "small and medium-sized enterprises")) and TITLE-ABS-KEY("service innovation" AND ("SME" OR "small and medium enterprise" OR "small and medium-sized enterprises")). Table 1 shows the query string search and the number of publications on each of the databases.

In order to guarantee the reliability of the study, only papers published in journals indexed onto the databases were considered for analysis in the SLR. Initially, relevant papers that mention innovation in services and SMEs without temporal restriction were selected. Then, it was decided to validate the query string search, as suggested by Kitchenham (2004). The papers in Table 2 were used as a control group, in turn offering us better amplitude and reliability of the terms when considering previously analyzed studies and correlated terms. Thus, the query string was validated when it was possible to obtain all the studies from the control group.

In this evaluation and validation process, 121 studies were identified, of which 32 were on the Web of Science database and 89 were part of the SCOPUS database. After conducting the pilot and obtaining potentially relevant studies, the following exclusion criteria were considered:

- C1: Any study that is not a complete paper published in journals or conference papers.

- C2: Any language other than English.

- C3: Papers that do not report on the theme being investigated (outside the scope of the research).

The survey of papers on the databases was carried out in March 2019 and relied on the simultaneous action of specialists in the management area and quantitative methods for decision-making. The research corpus was later compiled into an electronic spreadsheet, which highlighted the essential elements of each paper individually. The articles that were chosen by the databases were reviewed thoroughly and those most relevant to the search topic were chosen.

The citation indicators were coded according to the following elements: (i) year in which the paper was published; (ii) linked journal; (iii) title of the paper; (iv) number of

Table 1 Query's String search in the databases of the structured systematic review

\begin{tabular}{lll}
\hline Data base & Query's String & $\begin{array}{l}\text { Number of } \\
\text { publications }\end{array}$ \\
\hline $\begin{array}{l}\text { Web of } \\
\text { Science }\end{array}$ & $\begin{array}{l}\text { TS=("service innovation" AND ("SME" OR "small and medium enterprise" OR } \\
\text { "SCOll and medium-sized enterprises")) }\end{array}$ & 32 \\
SCOPUS & $\begin{array}{l}\text { TITLE-ABS-KEY("service innovation" AND ("SME" OR "Small and medium } \\
\text { enterprise" OR "small and medium-sized enterprises")) }\end{array}$ & 89 \\
Total & & 121 \\
\hline
\end{tabular}


Table 2 Validation of the query's string by using a pre-established control group

\begin{tabular}{|c|c|c|}
\hline Authors & Title & Indexing \\
\hline $\begin{array}{l}\text { McDermott and } \\
\text { Prajogo, } 2012\end{array}$ & Service innovation and performance in SMEs & $\begin{array}{l}\text { Web of Science } \\
\text { sCOPUS }\end{array}$ \\
\hline $\begin{array}{l}\text { Prajogo and } \\
\text { McDermott, } 2014\end{array}$ & $\begin{array}{l}\text { Antecedents of Service Innovation in SMEs: Comparing the Effects of } \\
\text { External and Internal Factors }\end{array}$ & $\begin{array}{l}\text { Web of Science } \\
\text { SCOPUS }\end{array}$ \\
\hline Suh and Kim, 2012 & $\begin{array}{l}\text { Effects of SME collaboration on R\&D in the service sector in open } \\
\text { innovation }\end{array}$ & $\begin{array}{l}\text { Web of Science } \\
\text { SCOPUS }\end{array}$ \\
\hline
\end{tabular}

citations of the paper; (v) name of the authors in the paper; (vi) number of authors; and (vii) country in which the authors of the study were working.

The content indicators were grouped into the following characteristics: (i) keywords cited in the paper; (ii) purpose of the paper; (iii) contribution of the paper; (iv) data collection procedure performed; (v) variables or categories of analysis used; (vi) main results of the study; (vii) limitations of the research; and (viii) suggestions for future research. Figure 1 shows a systematized flowchart of the research protocol containing the inclusion/exclusion criteria for collating the sample.

Initially, only $\mathrm{C} 1$ and $\mathrm{C} 2$ were used; $\mathrm{C} 3$ was applied at the end of the selection of the papers chosen for complete reading. After excluding the studies, the Web of Science and SCOPUS databases covered 32 and 63 works, respectively. However, some studies had already been identified in databases due to the way in which the search was performed. Eliminating duplicated studies within each database, there were 21 papers on the Web of Science database and 52 papers on the SCOPUS database. From this, a complete analysis of the available papers was performed, and then C3 was applied, eliminating 33 papers and leaving a final sample of 41 component papers from the corpus.

The analyses were performed using the computational resource RStudio 1.0.143. The codes used are available in Appendix A. More details can be found in the work of Aria and Cuccurullo (2017).

\section{Results and discussion}

Based on the specifications and criteria proposed in this work, some secondary research questions were elaborated and are presented throughout this section. In addition, the main results obtained from the sample of selected studies are presented, based on three classical bibliometric laws: Lotka's law (1926), which addresses the scientific productivity of authors; Bradford's law (1953), which exposes journals' productivity or the dissemination of literature; and Zipf's law (1949), which expresses the frequency or cooccurrence of words in the research corpus.

\section{Descriptive analysis of the research corpus}

The descriptive analysis of the corpus refers to the treatment of the indicators related to the citation and content of the work. Thus, the number of papers published over time, the geographical distribution of authors and countries, and the composition of authorship in the works of the corpus text were evaluated. 


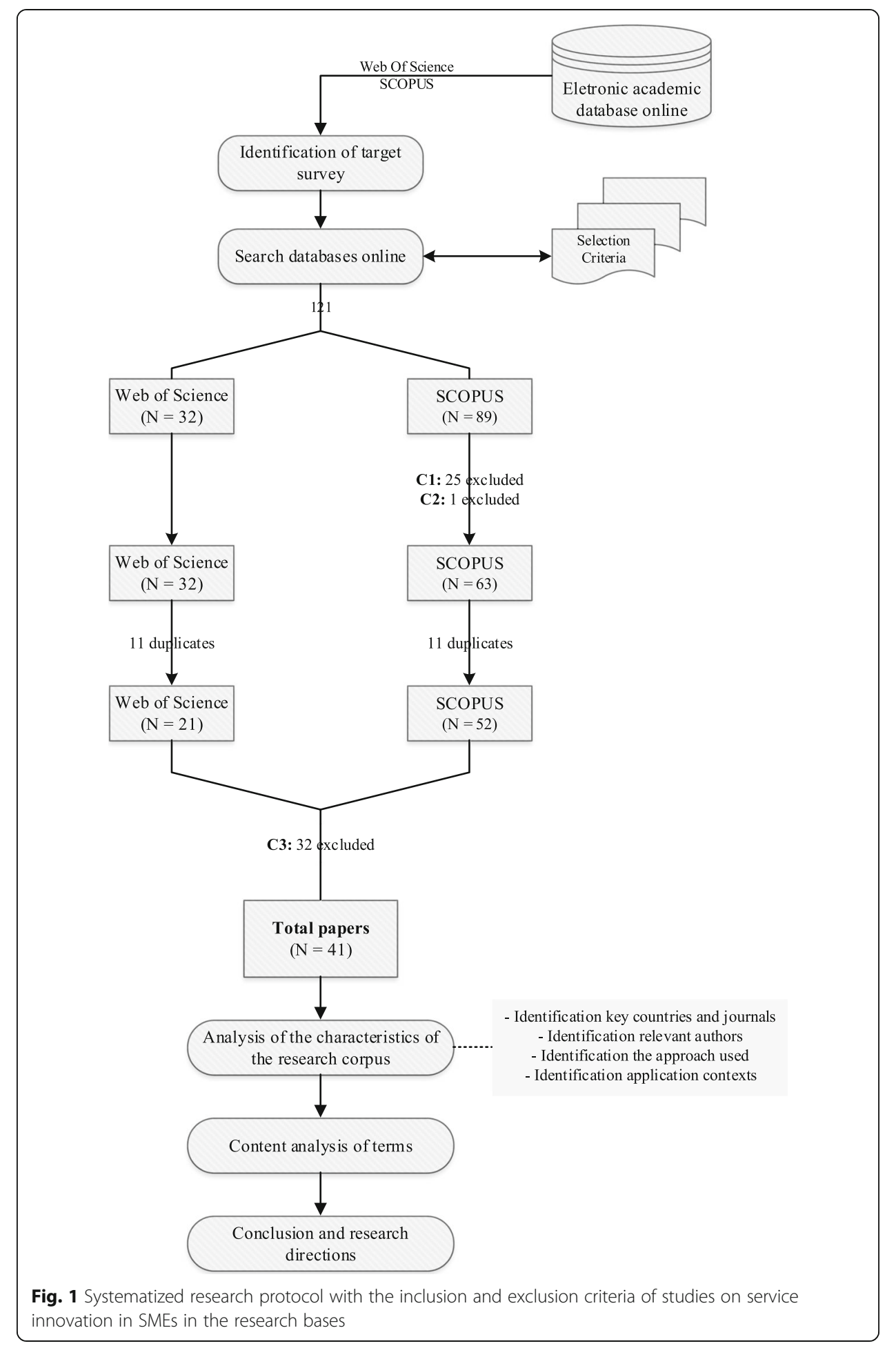

\section{Publication frequency per year}

Although the research was not carried out by applying temporal delimitation, it was found that the first publication record about the innovation of services in SMEs, with the criteria defined in the "Theoretical background" section, occurred 
in 2009, after which the number of publications presented a temporal evolution, as can be seen in Fig. 2 .

It is observed that, in the first 5 years that we evaluated, there was an increase in the number of published studies, corresponding to an average of 2.6 articles per year. In this period, the most outstanding work was developed by McDermott and Prajogo (2012) in the article "Service Innovation and Performance in SMEs," published in the International Journal of Operations \& Production Management, which received 36 citations.

Between 2014 and the third and fourth months of 2019, there is an average of 4.67 articles per year, showing a growth trend with fluctuations over the period. It is still possible to see that the largest number of publications occurred in 2014, corresponding to $21.95 \%$ of the total number of studies, followed by 2018 , with approximately $17.07 \%$ of published works. We can highlight the work developed by Prajogo and McDermott (2014), entitled "Antecedents of Service Innovation in SMEs: Comparing the Effects of External and Internal Factors" published in the Journal of Small Business Management, which obtained a total of 17 citations.

Based on the analyzed data and empirical evidence, the growth in research indicates the relevance that the theme has enjoyed in recent years. This increase in the number of publications is relevant to our understanding of the current state of the art of service innovation in SMEs. The analysis of the results prompted the following secondary research question: SQ1. Is there a growth in the interest in innovation in services from the perspective of SMEs?

\section{Analysis of journal productivity}

Bradford's law (1953) was used to analyze the journal productivity of the textual corpus, which relates to the decreasing order of the productivity of articles in scientific journals, enabling the establishment of clusters, which are divided exponentially. The number of journals in each group was proportional to $1: n: n^{2}$, in which it is possible to determine the core and the areas of dispersion on a given subject in the same set of journals.

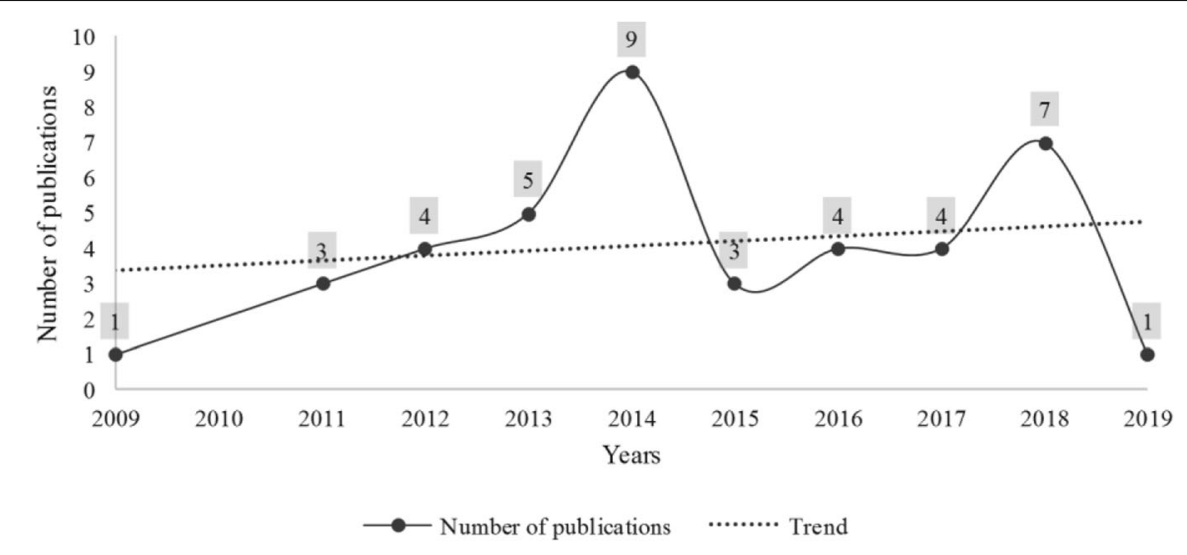

Fig. 2 Textual corpus annual distribution 
The 39 journals were classified in decreasing order of productivity and distributed into three zones, each with one third of the total papers (resulting in approximately 14 papers per zone). The first zone corresponded to approximately $30.7 \%$ of the corpus of the research, distributed across 12 journals, with an average of approximately 0.86 articles published per journal. Fourteen journals were allocated to the second zone, representing $35.90 \%$ of the research corpus, with an average of one paper published per period. A difference of $14.29 \%$ can be observed in journal productivity in the second zone when compared to the first, while the third zone referred to a total of 13 lessproductive journals with a maximum of one paper published, representing $33.33 \%$ of the research corpus. In this sense, we could not evidence the presence of the Bradford law since several journals had only one paper published in them, in addition to the proportion of papers belonging to the productivity zones being very close.

When analyzing productivity, we considered the articles published in journals relevant to the scientific community, classified according to all the citation quartiles of the Scimago Journal Ranking (SJR). It was found that the 41 papers in the text corpus were published in journals and qualified scientific events. In the case of journals, it was observed that $64.10 \%$ were in all the citation quartiles, according to the SJR (2019). The average $\mathrm{H}$ indices for the four quartiles in the last 3 years were 98.14 (Q1), 39 (Q2), 23 (Q3), and $16(\mathrm{Q} 4)$.

\section{Frequency of publication per journal}

Although SMEs play an important role in the economic development of any country and despite their contribution to a wide range of jobs and increasing GDP, there is scant empirical evidence on the process of innovation in services, especially from countries characterized as emerging (Halme, Lindeman, \& Linna, 2012; Hall et al., 2012; Halme et al., 2016). The works studied were distributed across 39 journals; only one work was published in 30 of them. Figure 3 shows the main 13 journals that contain the papers that constitute our analyzed corpus.

It is possible to observe that 18 papers $(46.15 \%)$ were concentrated in nine journals, that is, most of the papers (53.85\%) were distributed across different journals. When analyzing the scope of each journal with the performance segment of this research, it was possible to categorize the journals according to following approaches: business

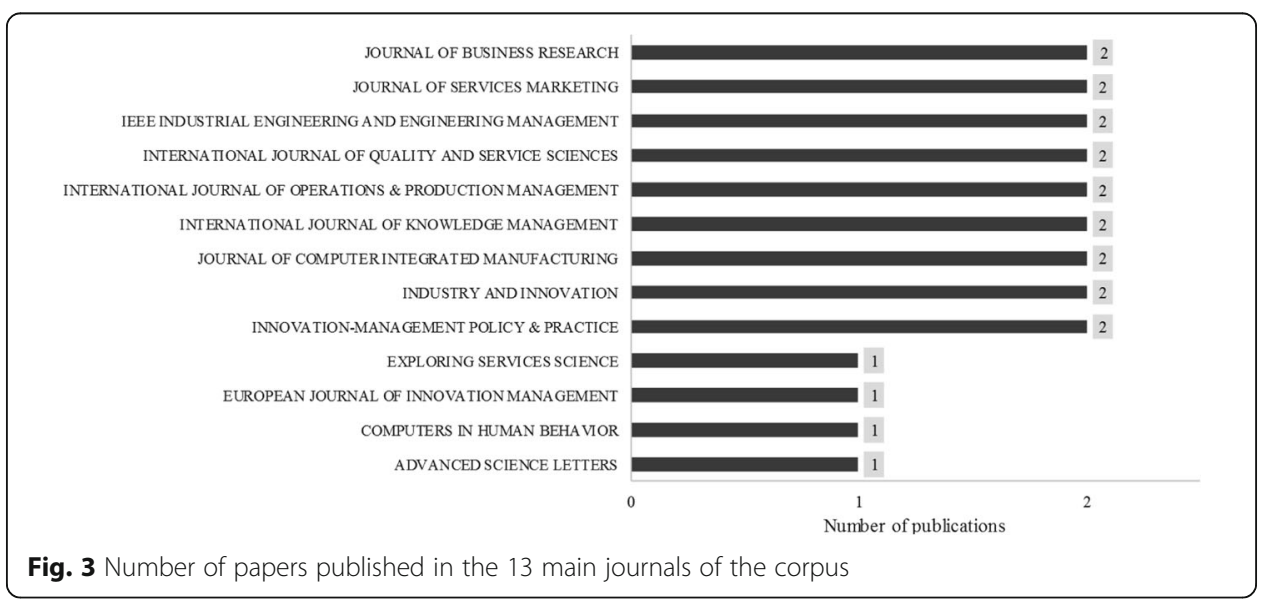


research, finance, organizational theory and behavior, marketing, international business, engineering, computer and information sciences, geosciences, energy, fuels and green engineering, among others. Interdisciplinarity does not eliminate the possibility that journals with a specific scope publish a study with a more holistic scope. The main journals, in terms of frequency of occurrence, were the following: Journal of Business Research, Journal of Services Marketing, Journal Industry and Innovation, Journal of Computer Integrated Manufacturing, International Journal of Knowledge Management, International Journal of Operations \& Production Management, International Journal of Quality and Service Sciences, and IEEE Industrial Engineering and Engineering Management.

It was observed that, of the 39 journals analyzed, 15 of them had an impact factor, according to the Journal Citation Reports: Journal of Business Research, Journal of Services Marketing, Advanced Science Letters, Computers in Human Behavior, European Journal of Innovation Management, Journal Industry and Innovation, Innovation: Management Policy \& Practice, International Journal of Computer Integrated Manufacturing, International Journal of Operations \& Production Management, Journal of Small Business Management, Small Business Economics, Journal of Product Innovation Management, Simulation Modelling Practice and Theory, and RED Management. They all had an impact factor in the last 5 years that was higher than the average unit, which means that the number of citations of papers published in these journals exceeded the number of papers published in them.

\section{Geographical distribution of papers and countries}

The geographical distribution of the authors who were part of the sample analyzed is related to the relationship that they had with research institutions and with established partnerships. It was possible to observe that some authors had different institutional relationships in different countries.

It was found that most studies were segmented into several institutions and, in this case, the Japan Advanced Institute of Science and Technology, the University of Camerino, Tamkang University, National Taipei University, National Central University, the University of Fukuchiyama, the Morita Tokyo MFG Corporation, and CAS Software AG were those that had collaborated most on the theme of service innovation in SMEs, with three papers published, totaling approximately $6.67 \%$ of the studies surveyed, from a total of 45 research institutions and partnerships evidenced. Figure 4 shows the geographical distribution of the authors of the studies related to the research theme.

Co-authorship is also used as an approximation of scientific collaboration between countries, and its use as a synonym for collaboration is somewhat controversial in the specialized literature, as it can lead to erroneous conclusions, since not all collaborative efforts result in co-authorship. Figure 5 presents the collaborative behavior of different researchers, evaluated according to the number of documents that were published on the theme relevant to the corpus.

Collaborations were divided into two types: those papers published by a single country represented $70 \%$ of the evaluated sample and involved no type of partnership, while $30 \%$ of the corpus corresponded to the sample of papers published in collaboration 


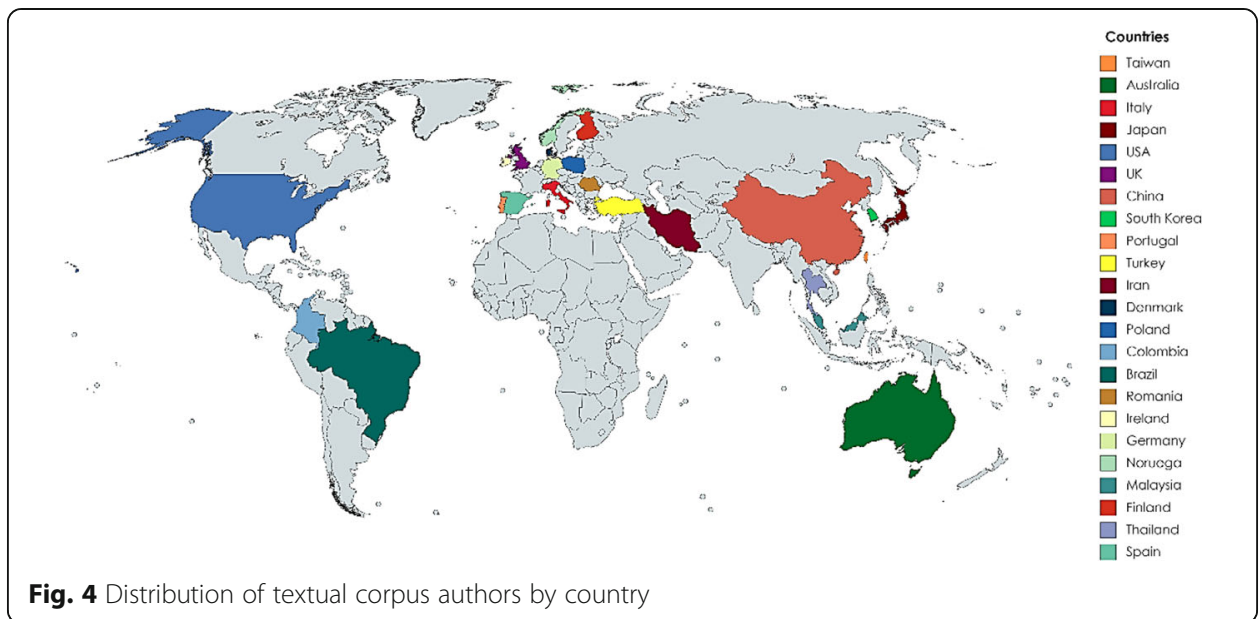

with authors from more than one country. Research institutions can also be evaluated according to nationality, in order to provide a bias concerning the regional origin of works, as shown in Fig. 6.

Twenty-three countries were identified, which implicated six continents: Europe (48.78\%), Asia (29.27\%), Oceania (7.32\%), North America (4.88\%), Eurasia (4.88\%), and South America (4.88\%). Therefore, the following secondary research question was raised: SQ2. Are there any advances in service innovation studies on SMEs on the European continent?

Figure 6 shows the data were clustered with the analysis of the information presented, which prompted us to ask the following secondary research question: SQ3. In Europe, does the UK stands out in relation to the number of studies on service innovation in SMEs due to the large amount of investment in research, development, and innovation and the interaction between universities, companies, and government institutions?

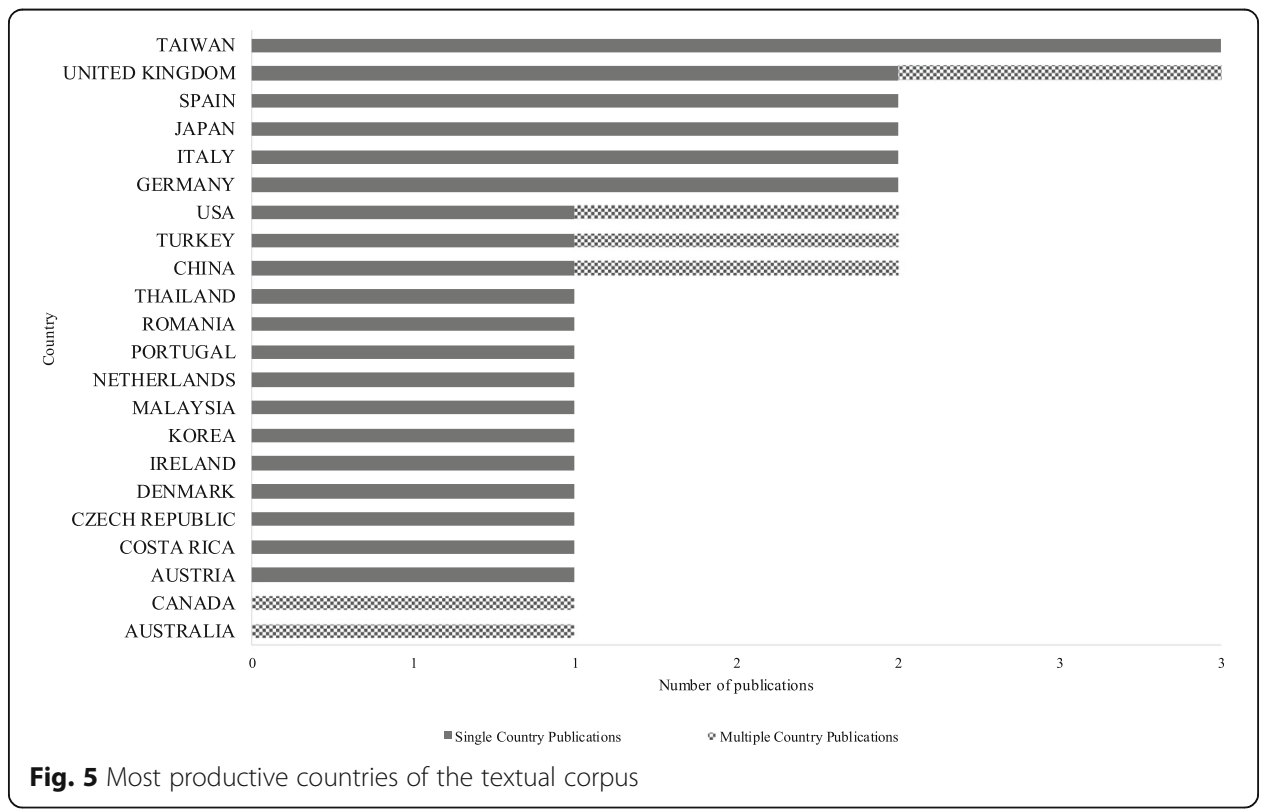




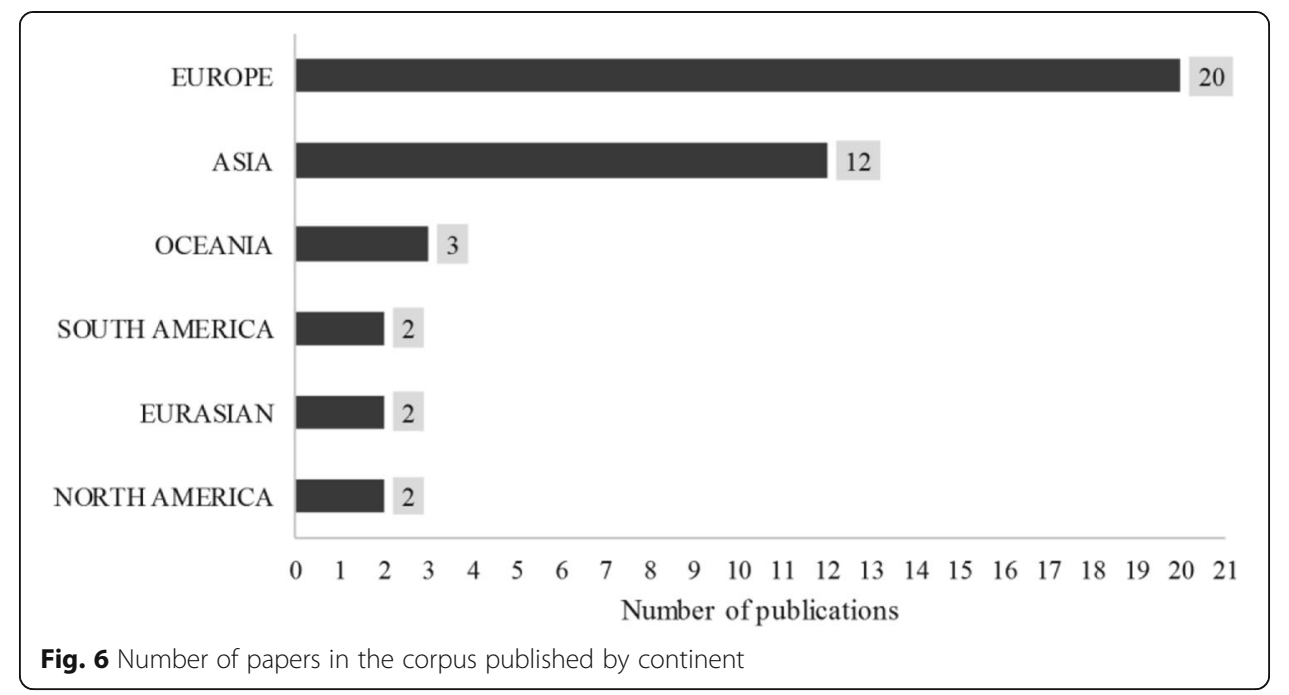

It was evidenced that several authors from institutions belong to the same country, which confirms Katz and Martin's (1977) theory that geographical proximity, culture, linguistic boundaries, customs, and sociopolitical issues lead to interactions between two or more partners, increasing the chances of co-publishing.

\section{Citation analysis of the research corpus}

This research used the number of citations as a bibliometric indicator to measure the productivity of authors and co-authors in the textual corpus, which as Zupic and Čater (2015) show, refers to the means of demonstrating influence in the academic community, since the authors cited documents that they considered important. The most relevant studies in the corpus which we analyzed were identified according to the citations received. Table 3 shows the 10 most cited and indexed papers on the Web of Science and SCOPUS databases.

This characteristic regarding the citation time period of the most recent papers can be justified due to some disciplines preferring to cite more productive papers, which in turn explains the differences in the citation rate among several areas of knowledge (Mugnaini, Carvalho, \& Campanatti-Ortiz, 2006).

The citation analysis of the authors of the published papers, which are part of this sample, reflects the nature and dynamics of publications, in addition to the importance attributed to this area of knowledge. To this extent, it was possible to develop the following secondary research question: SQ4. Is there a large field of application regarding the subject of innovation in services in SMEs from different perspectives?

\section{Co-citation analysis and co-occurrence of words}

The co-citation analysis of cited references was based on the protocol developed by Tranfield et al. (2003), Kitchenham (2004), and Biolchini et al. (2005). Such an evaluation, in the view of Small (1973), allowed us to identify the frequency at which two authors or journals are cited simultaneously in the scientific literature.

The references of all the authors cited in the studies that comprised the corpus were extracted in order to identify the most cited authors interested in the relationship 
Table 3 Top 10 of the most cited papers of the research corpus

\begin{tabular}{|c|c|c|c|}
\hline Title & Authors & Citation & Objective \\
\hline $\begin{array}{l}\text { Service innovation and performance in } \\
\text { SMEs }\end{array}$ & $\begin{array}{l}\text { McDermott and } \\
\text { Prajogo, } 2012\end{array}$ & 36 & $\begin{array}{l}\text { Examine the relationship between } \\
\text { innovation in exploration and business } \\
\text { performance in SMEs }\end{array}$ \\
\hline $\begin{array}{l}\text { The innovative model of the Virtual } \\
\text { Development Office for collaborative } \\
\text { networked enterprises: the GPT } \\
\text { network case study }\end{array}$ & $\begin{array}{l}\text { Saetta, Tiacci and } \\
\text { Cagnazzo, } 2013\end{array}$ & 19 & $\begin{array}{l}\text { Apply a management model with the } \\
\text { structure of the Virtual Development } \\
\text { Office (VDO) in SMEs }\end{array}$ \\
\hline $\begin{array}{l}\text { Antecedents of Service Innovation in } \\
\text { SMEs: Comparing the Effects of } \\
\text { External and Internal Factors }\end{array}$ & $\begin{array}{l}\text { Prajogo and } \\
\text { McDermott, } 2014\end{array}$ & 17 & $\begin{array}{l}\text { Examine empirically the organizational } \\
\text { factors associated with innovation } \\
\text { guidelines in SMEs }\end{array}$ \\
\hline $\begin{array}{l}\text { Effects of SME collaboration on R\&D in } \\
\text { the service sector in open innovation }\end{array}$ & Suh and Kim, 2012 & 15 & $\begin{array}{l}\text { Analyze the effects of collaborative } \\
\text { activities of SMEs of services in the } \\
\text { context of open innovation }\end{array}$ \\
\hline $\begin{array}{l}\text { You can lead a firm to R\&D but can } \\
\text { you make it innovate? UK evidence } \\
\text { from SMEs }\end{array}$ & Cowling, 2016 & 14 & $\begin{array}{l}\text { Question the adoption of tax credits } \\
\text { by SMEs and the increase of } \\
\text { innovations }\end{array}$ \\
\hline $\begin{array}{l}\text { Effectuation, innovation and } \\
\text { performance in SMEs: an empirical } \\
\text { study }\end{array}$ & $\begin{array}{l}\text { Roach, Ryman and } \\
\text { Makani, } 2016\end{array}$ & 13 & $\begin{array}{l}\text { Proposed a scale for measuring } \\
\text { innovation }\end{array}$ \\
\hline $\begin{array}{l}\text { A practical perspective on the } \\
\text { classification of service innovations }\end{array}$ & Hsieh et al., 2013 & 13 & $\begin{array}{l}\text { Investigated academic classifications of } \\
\text { service innovation }\end{array}$ \\
\hline $\begin{array}{l}\text { Inter-organizational information } \\
\text { systems adoption for service } \\
\text { innovation in building sector }\end{array}$ & $\begin{array}{l}\text { Chaparro-Peláez, } \\
\text { Pereira-Rama and } \\
\text { Pascual-Miguel, } \\
2014\end{array}$ & 11 & $\begin{array}{l}\text { Identify the factors that influence the } \\
\text { adoption of Interorganizational } \\
\text { Information Systems in SMEs to } \\
\text { promote more service innovation }\end{array}$ \\
\hline $\begin{array}{l}\text { Are trademark counts a valid indicator } \\
\text { of innovation? Results of an in-depth } \\
\text { study of new Benelux trademarks filed } \\
\text { by SMEs }\end{array}$ & $\begin{array}{l}\text { Flikkema, De Man } \\
\text { and Castaldi, } 2014\end{array}$ & 10 & $\begin{array}{l}\text { Expand the emerging literature on the } \\
\text { value of brands for innovation studies } \\
\text { in SMEs }\end{array}$ \\
\hline $\begin{array}{l}\text { Determinants of absorptive capacity: } \\
\text { contrasting manufacturing vs services } \\
\text { enterprises }\end{array}$ & $\begin{array}{l}\text { Chang, Chen and } \\
\text { Lin, } 2014\end{array}$ & 9 & $\begin{array}{l}\text { Explore the determinants and } \\
\text { consequent abortive capacity of } \\
\text { resource structure in manufacturing } \\
\text { and service industries }\end{array}$ \\
\hline
\end{tabular}

between innovation in services and SMEs. In this context, the aim was to answer the following question: what is the relationship between the 110 authors of the 1841 cited references in the 41 component papers of the corpus? The distribution of the relationship network among the authors cited simultaneously in the references was determined by the standard layout algorithms of the Fruchterman Reingold graphs (Fruchterman \& Reingold, 1991), as shown in Fig. 7. More details about the techniques applied can be found in the work of Cuccurullo, Aria, \& Sarto (2016).

Based on the distribution performed by the algorithm, the cited references were classified into three groups, according to the clustering coefficient, as shown in Prell (2012). In order to improve graphic visualization, a minimum of two was used as the criterion for edge connections. It is evident that the most cited authors in the works that comprised the corpus were Schumpeter (1934), Barney (1991), Damanpour (1992), Coombs and Miles (2000), Avlonitis, Papastathopoulou, and Gounaris (2001), Garcia and Calantone (2002), Agarwal, Erramilli, and Dev (2003), Vargo and Lusch (2008), Wolff and Pett (2006), and Oke (2007). This result converges with the aim of this study, which is to investigate the relationship between service innovation and SMEs, given that the works previously reported are specific to the investigated field. 


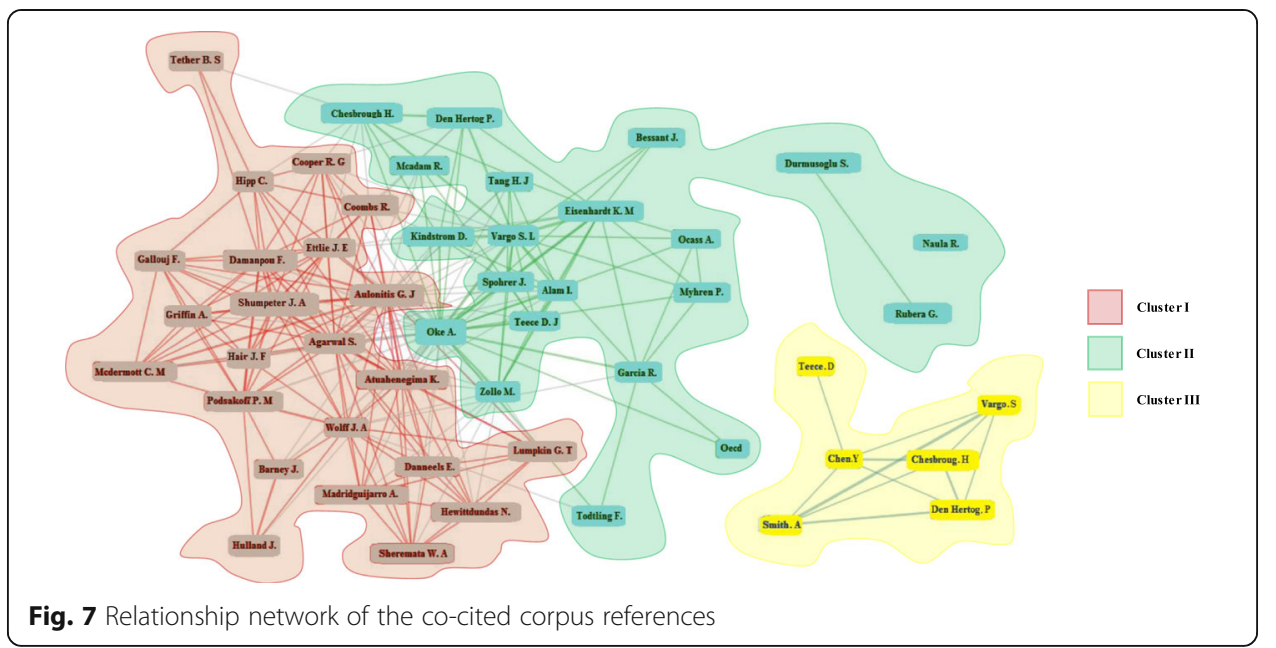

This finding suggests that the studies typically highlighted a very close theoretical relationship, and that there was convergence in the citation of classic authors on the topic under study, evidenced by the relationship between them. Other authors showed little connectivity, presenting the lowest number of adjusted connections concerning the relationship between service innovation and SMEs.

In addition, the co-citation analysis showed that the greater the number of component researchers in the corpus who cited the same two publications, the greater the probability that a double citation was not a random occurrence, which reflects the nature of the issue discussed in the publications cited within their areas of investigation, in this case, service innovation in SMEs.

The validity of the first Lotka bibliometric law (1926), which evaluates the productivity of the authors in a corpus, was observed, since approximately $98 \%$ of the authors/ co-authors published only one scientific paper, while approximately $2 \%$ of the authors/ co-authors produced two or more works.

When evaluating the co-occurrence of the words contained in the of the corpus papers, we first used a word cloud, which is a metric used to visually highlight the frequency at which terms in an analyzed text. Thus, the greater frequency of word usage in the text, the greater the word size in the cloud, i.e., the most frequent terms stand out and characterize the main keywords related to the given subject. This bibliometric technique highlights terms by considering the analyzed content, based on the bibliometric law of Zipf (1949), which was previously applied by Nang et al. (2015) to identify the main concepts in 23 records of global health engagement lessons. Further, Armfield et al. (2014) used the word cloud approach to identify emerging topics in two distinct periods.

Figure 8 presents the 100 most frequently occurring terms extracted from the of analyzed corpus, in which 1651 terms were constructed based on the word incidence matrix, and where the size of the terms was proportional to the frequency of occurrence.

It is observed that the terms identified have a direct relationship with service innovation in SMEs, with the most frequent words being innovation (164), which corresponds to $9.93 \%$ of the total frequencies calculated (1.651), followed by service (152) at 


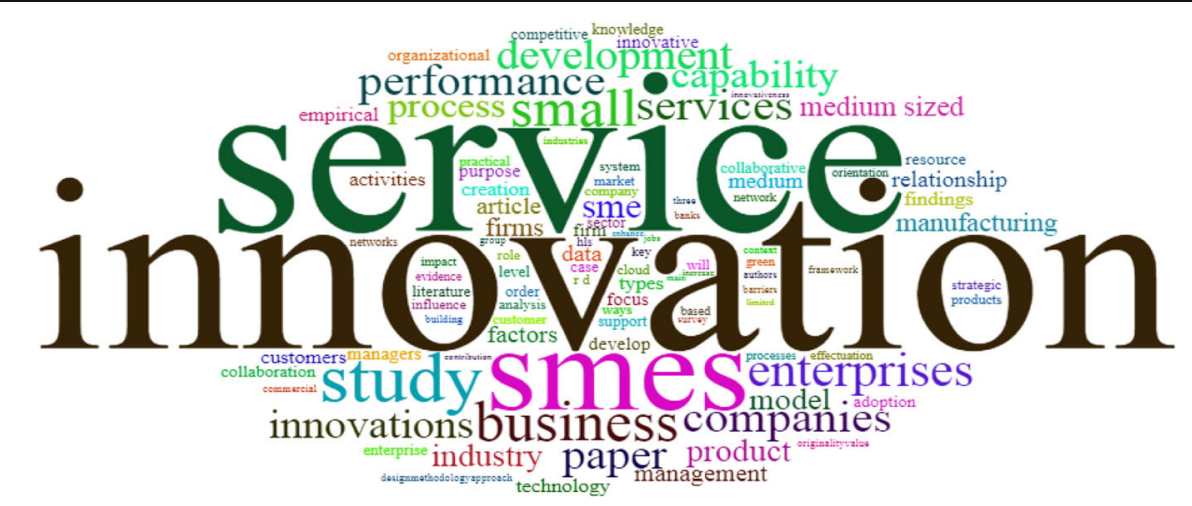

Fig. 8 Textual corpus word cloud

$9.21 \%$, SMEs (81) at $4.91 \%$, study (46) at $2.79 \%$, business (37) at $2.24 \%$, enterprises (32) at $1.94 \%$, companies (30) and performance (30) each at $1.82 \%$, development (28) at $1.70 \%$, process (24) at $1.45 \%$, industry (21) at $1.27 \%$, and factors (16) at $0.97 \%$. It should be noted that the 18 terms with the highest occurrences corresponded to approximately $50 \%$ of the total frequency of occurrences evaluated.

Correspondence analysis was also performed to measure the degree of association concerning the categorized variables arranged in the contingency tables. In addition, we identified the conceptual structure of the analyzed field, as well as formulating clusters of documents that expressed common concepts. The co-occurrence investigation into the researched terms allowed us to evaluate the topic in question and identify patterns in the searches performed (Aria and Cuccurullo, 2017). Figure 9 shows the formulation dendrogram of the clusters developed from the corpus.

It was possible to identify the formation of three clusters, comprising the most relevant terms of the researched set, obtained via a cross section of the greatest distance between the clusters. The first cluster was named "strategic pillars," formed by collaborative, strategic, types, activities, innovative, organizational, analyses, technology, competitive, SMEs, model, creation, and capability. The second cluster was called "adaptation strategies," consisting of: ways, enterprise, knowledge, business, customers, system, sector, develop, support, market, management, company, influence, factors, services, and adoption. The third cluster was called the "results strategy," consisting of firm, relationship, findings, industry, purpose, practical, innovation, role, empirical, process, study, level, literature, development, and resource.

It was verified that the three formulated groups were heterogeneous, indicating that there was homogeneity within each group and heterogeneity among the groups. In this case, the variables were clustered according to at least one characteristic they had in common. Some important findings can be evidenced: (a) SMEs were presented as the central object of the studies; (b) the results related to investigating the relationship between innovation processes in services and improvements in organizational performance; (c) studies on innovation in services were related to the ways of developing business knowledge; and (d) the recurrence of the terms management, innovation, and case pointed to research aimed at the development of new approaches.

Based on the corpus extracted from the papers, it was decided to map the research field explored. In doing so, we considered the most evidenced terms in the textual 


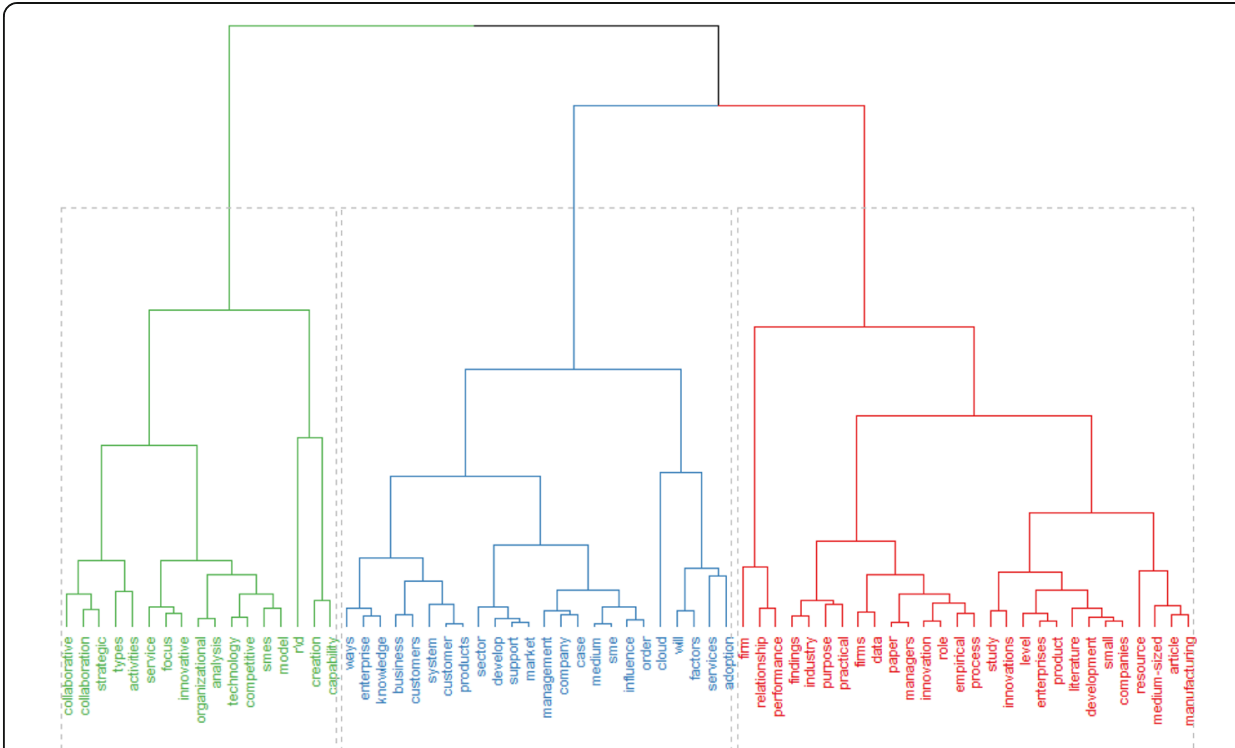

Fig. 9 Formulation of clusters according to the frequency of occurrence

corpus, through a two-dimensional diagram related to its centrality and density classification. More details on this procedure can be found in the works developed by Cobo et al. (2011). This conceptual structure is often used to understand the topics addressed by researchers and identify the most important and most recent issues. The twodimensional diagram was divided into quadrants, as shown in Fig. 10.

Topics in the upper-right quadrant are well developed and important in terms of structuring a research field. In the same context, such topics are characterized as "motor topics" of the subject in question, since they present strong centrality and high density. The topics present in this quadrant imply that they are externally related to concepts applicable to other topics. Thus, the term process is presented in this quadrant. When deeply analyzing cases of process innovations in service companies, it was found that these innovations follow a similar logic in relation to those reported in the literature concerning physical goods (Tiid and Hull, 2005; Cobo et al., 2011).

Topics located in the upper-left quadrant have well-developed internal links, as well as unimportant external links, and are therefore characterized as being of marginal importance only to the field. These topics are characterized as being of a specialized and secondary character. This research found terms such as companies, focus, and SME. Secondary studies seek to establish conclusions based mainly on case studies, leading to a summary of findings that are common to them. Thus, it was observed that, in our specific case, the terms located in this quadrant present a link with previous studies on the search for subsidies to raise awareness of the application of service innovation in SMEs.

Topics located in the lower-left quadrant are weakly developed and marginal; they also have low density and low centrality, as they mainly represent emerging or endangered topics. The term development is observable in this quadrant and refers to efforts made in recent years to build a theory of innovation in services or identify common points for development. 


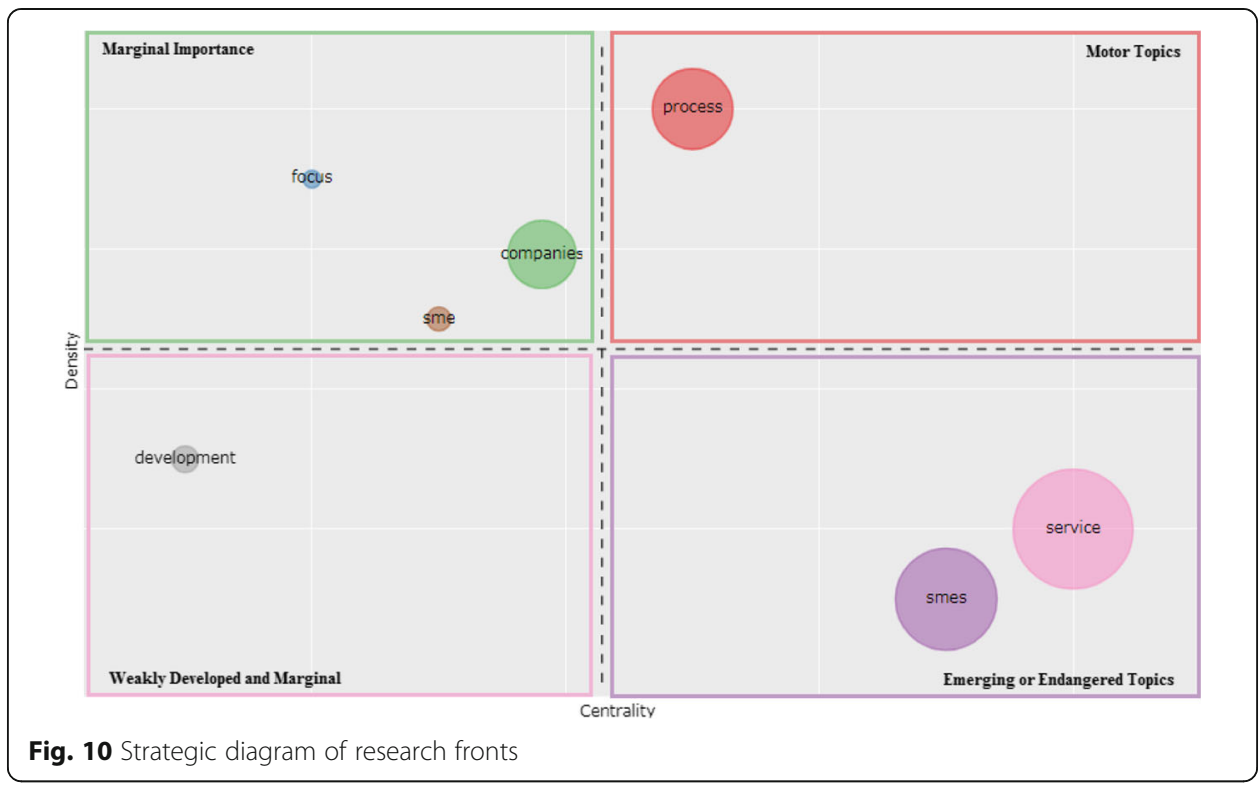

Topics located in the lower-right quadrant are important to the research field in question, but have not yet been developed; thus, they are referred to as transversal, general, and basic topics. The terms covering the investigated typology were service and $S M E$, which are in line with the aim of the study. Over the years, the symmetry between the process of innovation in services and SMEs has been consolidated, with market dynamics influencing the emergence of knowledge as a factor supporting the development of innovation. This information contributed to the elaboration of the following secondary research question: SQ5. Is there evidence of the importance of developing new studies on innovation in services from the perspective of SMEs?

Subsequently, we sought to complement previous analyses by identifying the patterns regarding the use of investigation methods in research on service innovation in SMEs. For this purpose, the 41 studies in the corpus were evaluated, and the necessary information to perform this analysis was extracted. Figure 11 presents the main evaluation techniques used in the studies.

It was observed that the methods used were categorized into two large groups: qualitative and/or quantitative. In terms of qualitative approaches, we subdivided this category into surveys that use questionnaires for data collection or those that use interviews. Thus, when the studies were carried out using questionnaires, the approaches were (a) secondary analyses, (b) exploratory approaches, (c) crosssectional studies, (d) case studies, and (f) thematic analyses. When the data were collected through interviews, the approaches used were (g) content analyses, (h) inductive and deductive analyses, (i) analytical techniques, and (j) causal logic, as employed in case studies.

Kreuzer and Aschbacher (2011) presented an empirical proposal for service innovation based on a systematic strategy, with specific management tools and methodologies, for application in three European countries, noting that the key factor with the greatest effect on service performance is the adoption of a service development strategy. 


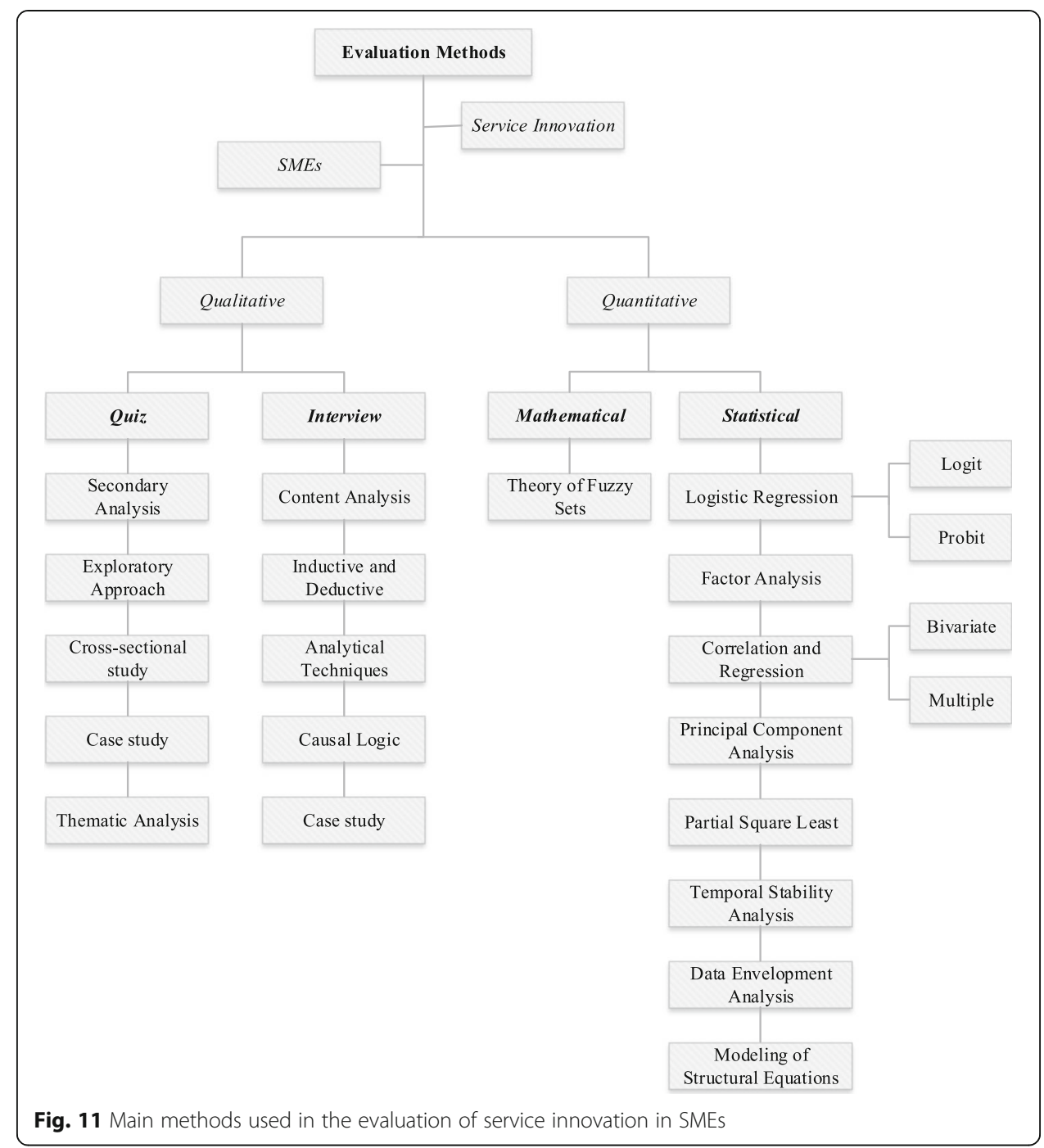

Koudelková and Milichovský (2014) identified the most commonly used and known methods to measure the effectiveness of innovation in services. To achieve these conditions, they used the secondary analysis of papers, as well as conducted primary research on randomly selected companies. For data collection purposes, they administered 321 questionnaires among SMEs. The authors found that successful innovation is only possible when using metrics such as patent counts or investment in research and development, and when the number of innovations generated over time is seen as relevant.

Hsieh and Chou (2018) evaluated the theory based on the resources used to build models by applying the technique of systems dynamics for SMEs before and after innovation in services, in order to develop a set of evaluation mechanisms. As methodological procedures, the following techniques were used: systems dynamics, deep interviews, causal logic, and causal cycle diagrams. The research results showed that SMEs face operational difficulties due to globalization. Consequently, they must invest appropriate resources to develop market adaptability, to be able to apply knowledge, to foster collaborative skills and to effectively apply information technology. 
The quantitative methods were classified into two groups: mathematical and statistical. In termss of mathematical methods, the fuzzy set theory was applied. Chester Goduscheit and Faullant (2018) verified how manufacturing companies can introduce radical innovations in services to the market by conducting 24 interviews with managers of SMEs, using inductive and deductive approaches, as well as applying the fuzzy set theory to evaluate the data. The authors concluded that there is a need to identify immediate customers as the main driver of service innovation.

Statistical models were the ones that presented the greatest coverage concerning their application. The statistical techniques identified were (a) logistic regression (logit or probit link functions), (b) factor analysis, (c) correlation and regression analysis (bivariate or multiple), (d) principal component analysis, (e) partial least squares, (f) time stability analysis, (g) data envelopment analysis, and (h) structural equation modeling.

The study developed by Cowling (2016) aimed to verify whether or not tax credits lead to an increase in innovations in services. The data were obtained via the Small Business Survey, which is a UK government data set for SMEs, as well as conducting a transversal survey using correlation analysis, the Kaiser-Meyer-Olkin test, and logistic regression (probit). The author noted that there is little additional service innovation which could justify tax spending, given the current credit distribution, but there is evidence of advanced innovations in more radical processes.

The work described by Nada and Ali (2015) aimed to explore the relationship between the ability to create value regarding services, along with service innovation capacity, and the ability to evaluate service innovation using a model proposed for value creation capacity. A questionnaire was administered among 116 companies, using the correlation analysis technique. They found that there is a strong positive correlation between the capacity for innovation in services of SMEs and the ability to create service value (strategic capacity, management capacity, operational capacity, and adaptive capacity).

It was observed that the most evidenced fields of application are financial and insurance services, wholesale and retail trade, construction, hotels, food, media and telecommunications, professional, scientific and technical services, public administration and security, education and training, healthcare and social assistance, transportation, postal and storage services, electricity, gas, water and waste services, collaboration in research and development, biotechnology, green energy, and tourism, creativity, and culture, thus indicating the multidisciplinary nature of the research object and the vast field of theoretical and practical applications.

For the analyzed corpus, it was possible to verify that quantitative approaches were the most used by researchers in their investigations into the processes of service innovation in SMEs. The use of logistic regression, structural equation modeling, correlation analysis, and regression techniques was more frequent. Such evidence can be explained by the technological evolution and data processing that have been taking place in recent years. To this extent, the following secondary research question can be established: SQ6. Is there evidence of a preference among researchers in using quantitative approaches with the application of statistical models?

This study reported six secondary research questions whose answers provide evidence about future perspectives on the subject being addressed, in addition to uncovering possible insights into the potential developmental work. 


\section{Conclusion, implication, and recommendations}

Literature mapping favors structured research which helps in understanding the stages developed, by promoting the replication of studies by other researchers who are interested in the subject being investigated, as well as expanding and disseminating knowledge. The research achieved the proposed aim by identifying the relevant issues described in the analyzed papers and diagnosing the current situation of the subject in question.

The increase in the number of studies on service innovation in SMEs has become a reality in the academic and professional environments. The need to assimilate the processes in service innovation is fundamental in the SME context. In our case, it was possible to observe that certain researchers are seeking to develop their studies in order to identify the main elements of these processes, to suggest methodologies in pursuit of improvements, and to propose new strategies for application in different segments.

Among the main results, some aspects, which answer the questions we initially proposed, are especially noteworthy. The first concerns the relevance that the subject has been enjoying in recent years, due to the growth in the number of studies. This increase is extremely important to any understanding of the current state of the art in service innovation in SMEs.

The scientific fields covered by the studies were business research, finance, organizational theory and behavior, marketing, international business, engineering, computer and information sciences, geosciences, energy, fuels, and green engineering. This aspect shows that the subject of service innovation in SMEs has an interdisciplinary character and involves researchers from different areas of science. Moreover, we noted an approximation collaborative in studies of research institutions and private companies, which favors the development of new technologies and projects and the provision of specialized services.

The authors whose work stood out regarding this topic were McDermott and Prajogo (2012), Saetta, Tiacci, and Cagnazzo (2013), Prajogo and McDermott (2014), Suh and Kim (2012), Cowling (2016), Roach, Ryman, and Makani (2016), Hsieh et al. (2013), ChaparroPeláez et al. (2014), Flikkema, De Man, and Castaldi (2014), Chang, Chen, and Lin (2014), and Mugnaini, Carvalho, and Campanatti-Ortiz (2006). Furthermore, it was evidenced that the most co-cited authors in the works in the corpus were Adegoke Oke, Gerard George, Avlonitis, James A. Wolff, Sanjeev Agarwal, Stephen L. Vargo, Fariborz Damanpour, Kwaku Atuahene-Gima, Joseph Alois Schumpeter, John Ettlie, and Rosanna Garcia.

The findings from the co-occurrence analysis of terms present in the textual corpus reveal a greater focus on the following applications: innovation, service, SMEs, study, business, enterprises, companies, performance, development, process, industry, and factors, in turn demonstrating thematic alignment with the frequency of terms used by the authors. The research carried out identified patterns with the formation of three clusters. The first cluster was classified as "strategic pillars," the second as "adaptation strategies," and the third as the "results strategy."

Regarding the subject mapping of the research field, we verified that innovation follows a similar logic in relation to innovations found in the literature on physical properties (Tiid and Hull, 2005). The terms reveal a link with previous studies on the search for subsidies to better understand the application of service innovation in SMEs. In recent years, efforts have been expended to create a theory of innovation in services or identify common areas of development, while market dynamics have influenced the emergence of knowledge as a factor supporting innovation development. Quantitative 
methods are clearly dominant in this research field. The use of logistics regression, structural equation modeling, correlation analysis, and regression is more frequent compared to qualitative approaches.

\section{Limitations and future work}

The results from the study should be considered alongside the limitations of this research. Despite the growth in the number of publications on service innovation in SMEs in recent years, we were limited by the size sample of the analyzed papers, due to the reduced number of papers published, even where innovation in services is linked with other innovation processes, such as products and processes, by some authors. It was observed that the number of papers evaluated was not high, due to the subject being at the evolutionary stage.

Regarding the particularities of this theoretical mapping, it can be said that the results from the in-depth research in the textual corpus. These results reveal some proposals that may lead to the development of future research involving the theme of service innovation in SMEs in the most different approaches. These proposals are segmented in the following directions for future research:

(a) Investigate how service innovations in small and medium-sized companies are adopted and disseminated both theoretically and, in the market, seeking to uncover the main barriers to innovation. This would allow companies from developed or developing countries to better understand the differences in terms of perceived cultural barriers and leadership styles. Additionally, assess which specific innovation fields are most relevant to the service sector.

(b) When conducting research in small companies, it is suggested that they may be involved in horizontal networks with competitors in order to manage risks, in serving different markets or even in joining forces against competitors, thus investigating this relationship between company's effectiveness and innovation networks that are so complex. In this sense, variables such as sector, field of knowledge, strategies, experience, type of innovation, country, age of the company, and its size can be taken into account when structuring a research and seeking to understand the different causal relationships.

(c) It is suggested to evaluate the operating conditions of a given sector when building a service innovation system that is consistent with real-world operations. This would improve the effectiveness of implementing service innovation in different sectors, as the feasibility and adequacy of implementing service innovation would be assessed, comparing the effects of different industries, adding sophistication, and scope to the field of service innovation.

Although the works presented in the textual corpus supported the development of a complex theoretical mapping of the literature in the field of service innovation in SMEs, this article presents opportunities for the improvement of new ideas for the development of new research that contribute to the management of innovation organizational, either incrementally or radically.

This study generally analyzed innovation in services in SMEs from an interdisciplinary point of view. Further, the application and sequence of the methods of analysis used 
were subjective, since they considered the experience and the context of application of researchers. The keywords used when searching in databases should also have included other words to capture the service characteristics.

All guidelines which were detailed in this document have been followed systematically. For the development of futures research, it is suggested to incorporate studies from other databases or journals evaluating new protocols in different contextual areas, and that can be analyzed individually. We recommend carrying out a statistical analysis using the secondary research questions we asked in this paper, but with an expansion in the size of the sample of analyzed papers.

\section{Appendix A}

The codes used are to convert databases into a single file (csv.) and to remove duplicate papers. The command "biblioshiny" allowed filtering of data, sources, authors and documents in an analytical way. A structured conceptual, intellectual and social analysis was used. The analyses are based on the study developed by Aria and Cuccurullo (2017).

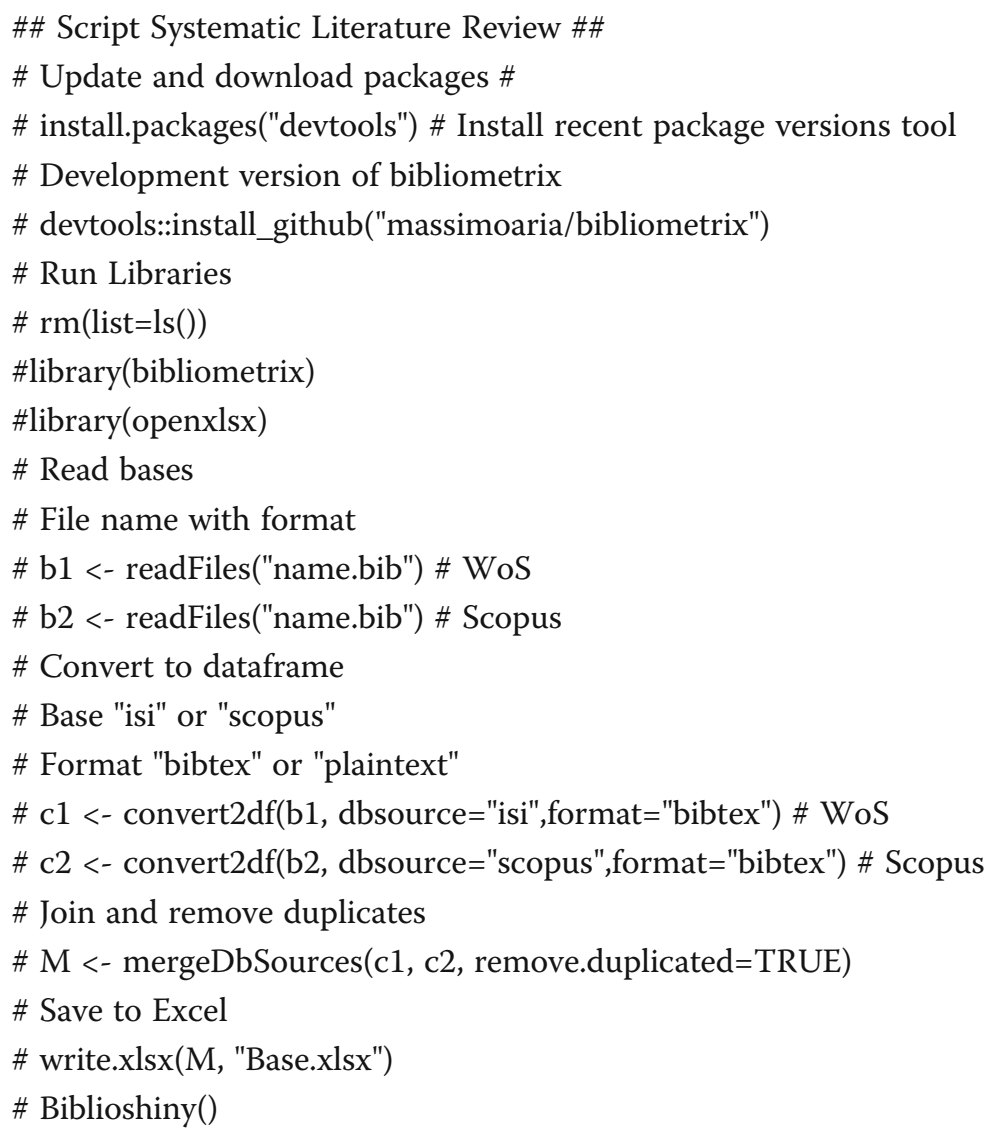




\section{Authors' contributions}

SROS: Conceptualization, methodology, software, validation, formal analysis, investigation, data curation, writing —original draft, writing—review and editing, visualization, supervision, project administration. WVS: conceptualization, investigation, data curation, visualization, supervision. CPV: conceptualization, investigation, data curation, visualization, supervision. RRZ: conceptualization, methodology, software, validation, formal analysis, investigation, data curation, writing_original draft, writing—review and editing, visualization, supervision, project administration.

\section{Funding}

Not applicable.

\section{Availability of data and materials}

Datasets for this study are available and the same can be obtained from a corresponding author on reasonable request. The dataset generated and analysed during the current study are available in the Web of Science and SCOPUS repository

\section{Competing interests}

The authors declare that they have no competing interests.

\section{Author details}

${ }^{1}$ Statistics Department, Federal University of Santa Maria - UFSM, Building, 13, Office 1205 C - CCNE, Roraima Ave, 1000, Santa Maria, RS, Brazil. ${ }^{2}$ Department of General Applied Administration, Federal University of Parana - UFPR, Lathório Meissner Ave, 632, Curitiba, PR, Brazil. ${ }^{3}$ Post-Graduation Program of Production Engineering, Federal University of Santa Maria, UFSM, Roraima Ave, 1000, Santa Maria, RS 97105-100, Brazil.

\section{Received: 6 March 2020 Accepted: 14 September 2020}

Published online: 22 September 2020

\section{References}

Agarwal, S., Erramilli, M., \& Dev, C. (2003). Market orientation and performance in service firms: role of innovation. Journal of Services Marketing, 17(1), 68-82. https://doi.org/10.1108/08876040310461282.

de Almeida Biolchini, J., Mian, P., Natali, A., Conte, T., \& Travassos, G. (2007). Scientific research ontology to support systematic review in software engineering. Advanced Engineering Informatics, 21, 133-151.

Antúnez-de-Mayolo, C. (2012). The role of innovation at the bottom of the pyramid in Latin America: eight case studies. Procedia-Social and Behavioral Sciences, 40, 134-140. https://doi.org/10.1016/j.sbspro.2012.03.172.

Aria, M., \& Cuccurullo, C. (2017). bibliometrix: An R-tool for comprehensive science mapping analysis. Journal of Informetrics, 11, 959-975. https://doi.org/10.1016/j.joi.2017.08.007.

Armfield, N., Edirippulige, S., Caffery, L., Bradford, N., Grey, J., \& Smith, A. (2014). Telemedicine-a bibliometric and content analysis of 17,932 publication records. International Journal of Medical Informatics, 83, 715-725. https://doi.org/10.1016/j. ijmedinf.2014.07.001.

Avlonitis, G., Papastathopoulou, P., \& Gounaris, S. (2001). An empirically-based typology of product innovativeness for new financial services: success and failure scenarios. Journal of Product Innovation Management, 18(5), 324-342.

Bardin, L. (2011). Análise de conteúdo. São Paulo: Edições, 70.

Barney, J. (1991). Firm resources and sustained competitive advantage. Journal of Management, 17(1), 99-120. https://doi.org/ 10.1108/EJIM-12-2014-0119.

Bettencourt, L., Brown, S., \& Sirianni, N. (2013). The secret to true service innovation. Business Horizons, 10(4), 110-135. https:// doi.org/10.5773/rai.v10i4.950.

Bianchi, M., Campodall'Orto, S., Frattini, S., \& Vercesi, P. (2010). Enabling open innovation in small-and medium-sized enterprises: how to find alternative applications for your technologies. R\&D Management, 40(4), 414-431. https://doi.org/ 10.1111/j.1467-9310.2010.00613.x.

Biolchini, J., Mian, P., Natali, A., \& Travassos, G. (2005). Systematic review in software engineering. System Engineering and Computer Science Department COPPE/UFRJ, 679, 45.

Blommerde, T., \& Lynch, P. (2014). Dynamic capabilities for managing service innovation: towards a conceptual framework. pp. 3-5.

Brandão, S., \& Bruno-Faria, M. (2013). Inovação no setor público: análise da produção científica em periódicos nacionais e internacionais da área de administração. Revista de Administração Pública, 47(1), 227-248. https://doi.org/10.1590/S003476122013000100010.

Carlborg, P., Kindström, D., \& Kowalkowski, C. (2014). The evolution of service innovation research: a critical review and synthesis. The Service Industries Journal, 34(5), 373-398. https://doi.org/10.1080/02642069.2013.780044.

Chang, C., Chen, Y., \& Lin, M. (2014). Determinants of absorptive capacity: contrasting manufacturing vs services enterprises. R\&D Management, 44, 466-483. https://doi.org/10.1111/radm.12086.

Chaparro-Peláez, J., Pereira-Rama, A., \& Pascual-Miguel, F. (2014). Inter-organizational information systems adoption for service innovation in building sector. Journal of Business Research, 67, 673-679. https://doi.org/10.1016/j.jbusres.2013.11.026.

Charles, N., Ojera, P., \& David, O. (2015). Factors influencing choice of strategic management modes of small enterprises Journal of Innovation and Entrepreneurship, 4(4). https://doi.org/10.1186/s13731-014-0016-y.

Chester Goduscheit, R., \& Faullant, R. (2018). Paths toward radical service innovation in manufacturing companies-a servicedominant logic perspective. Journal of Product Innovation Management, 35, 701-719. https://doi.org/10.1111/jpim.12461

Cobo, M., López-Herrera, A., Herrera-Viedma, E., \& Herrera, F. (2011). An approach for detecting, quantifying, and visualizing the evolution of a research field: A practical application to the fuzzy sets theory field. Journal of Informetrics, 5, 146-166. https://doi.org/10.1016/j.joi.2010.10.002. 
Coombs, R., \& Miles, I. (2000). Innovation, measurement and services: the new problematique. Em Innovation systems in the service economy (pp. 85-103). Boston, MA: Springer.

Cowling, M. (2016). You can lead a firm to R\&D but can you make it innovate? UK evidence from SMEs. Small Business Economics, 46, 565-577. https://doi.org/10.1007/s11187-016-9704-2.

Cuccurullo, C., Aria, M., \& Sarto, F. (2016). Foundations and trends in performance management. A twenty-five years bibliometric analysis in business and public administration domains. Scientometrics, 108, 595-611. https://doi.org/10.1007/s11192-016-1948-8.

Damanpour, F. (1992). Organizational size and innovation. Organization Studies, 13(3), 375-402.

Den Hertog, P., Van der Aa, W., \& De Jong, M. (2010). Capabilities for managing service innovation: towards a conceptual framework. Journal of Service Management, 21(4), 490-514.

Etzkowitz, H., \& Leydesdorff, L. (1995). The triple helix-university-industry-government relations: a laboratory for knowledgebased economic development. EASST Review, 14(1), 14-19.

Etzkowitz, H., \& Leydesdorff, L. (2000). The dynamics of innovation: from national systems and "mode 2" to a triple helix of university-industry-government relations. Research Policy, 29, 109-123.

Fixari, D., \& Pallez, F. (2016). A public strategy under construction? coordination and performance in territorial innovation systems. International Review of Administrative Sciences, 82(3), 418-434. https://doi.org/10.1177/0020852315597774.

Flikkema, M., De Man, A., \& Castaldi, C. (2014). Are trademark counts a valid indicator of innovation? Results of an in-depth study of new benelux trademarks filed by SMEs. Industry and Innovation, 21, 310-331. https://doi.org/10.1080/13662716. 2014.934547.

Fruchterman, T., \& Reingold, E. (1991). Graph drawing by force-directed placement. Software: Practice and experience, 21, 1129-1164. https://doi.org/10.1002/spe.4380211102.

Fusco, E., Coneglian, C., \& Mucheroni, M. (2017). Informacional do ecossistema paulista de inivação: modelo computacional e semântico de apoio à inovação. XVIII Encontro Nacional de Pesquisa em Ciência da Informação (pp. 1-20). Marília: ENANCIB.

Gallouj, F., Weber, K., Stare, M., \& Rubalcaba, L. (2016). The futures of the service economy in Europe: A foresight analysis. Technological Forecasting and Social Change, 94, 80-96. https://doi.org/10.1016/j.techfore.2014.06.009.

Garcia, R., \& Calantone, R. (2002). A critical look at technological innovation typology and innovativeness terminology: a literature review. Journal of Product Innovation Management, 19(2), 110-132.

Glänzel, W. (2007). Characteristic scores and scales: A bibliometric analysis of subject characteristics based on long-term citation observation. Journal of Informetrics, 1, 92-102. https://doi.org/10.1016/j.joi.2006.10.001.

Gunday, G., Ulusoy, G., Kilic, K., \& Alpkan, L. (2011). Effects of innovation types on firm performance. International Journal of Production Economics, 133(2), 662-676. https://doi.org/10.1016/j.ijpe.2011.05.014.

Hall, J., Matos, S., Sheehan, L., \& Silvestre, B. (2012). Entrepreneurship and innovation at the base of the pyramid: a recipe for inclusive growth or social exclusion? Journal of Management Studies, 49, 785-812. https://doi.org/10.1111/j.1467-6486.2012.01044.x.

Halme, M., Lindeman, S., \& Linna, P. (2012). Innovation for inclusive business: Intrapreneurial bricolage in multinational corporations. Journal of Management Studies, 49, 743-784. https://doi.org/10.1111/j.1467-6486.2012.01045.x.

Halme, M., Kourula, A., Lindeman, S., Kallio, G., Lima-Toivanen, M., \& Korsunova, A. (2016). ustainability innovation at the base of the pyramid through multi-sited rapid ethnography. Corporate Social Responsibility and Environmental Management, 23, 113-128. https://doi.org/10.1002/csr.1385.

Hill Bradford, A. (1953). Observation and experiment. New England Journal of Medicine, 248(24), 995-1001. https://doi.org/10. 1056/NEJM195306112482401.

Hsieh, Y., \& Chou, Y. (2018). Modeling the impact of service innovation for small and medium enterprises: A system dynamics approach. Simulation Modelling Practice and Theory, 82, 84-102. https://doi.org/10.1016/j.simpat.2017.12.004.

Hsieh, J., Chiu, H., Wei, C., Rebecca Yen, H., \& Cheng, Y. (2013). A practical perspective on the classification of service innovations. ournal of Services Marketing, 27, pp. 371-384. https://doi.org/10.1108/JSM-10-2011-0159.

Ivanova, I., \& Leydesdorff, L. (2014). simulation model of the Triple Helix of university-industry-government relations and the decomposition of the redundancy. Scientometrics, 99, 927-948. https://doi.org/10.1007/s11192-014-1241-7.

Katz, J., \& Martin, B. (1977). What is research collaboration? Research Policy, 26(1), 1-18. https://doi.org/10.1016/S00487333(96)00917-1.

Kitchenham, B. (2004). Procedures for performing systematic reviews. Keele University, 33, 1-26.

Kitchenham, B., \& Charters, S. (2007). Guidelines for performing systematic literature reviews in software engineering. Technical report, EBSE Technical Report.

Kitchenham, B., Brereton, O., Budgen, D., Turner, M., Bailey, J., \& Linkman, S. (2009). Systematic literature reviews in software engineering-a systematic literature review. Information and Software Technology, 51, 7-15. https://doi.org/10.1016/j.infsof. 2008.09.009.

Koudelková, P., \& Milichovský, F. (2014). Appropriate Methods for Measurement Effectiveness of Innovation in SMEs in the Czech Republic. Vision 2020: Sustainable Growth, Economic Development, and Global Competitiveness, (pp. 976-987)

Kreuzer, E., \& Aschbacher, H. (2011). Strategy-based service business development for small and medium sized enterprises. International Conference on Exploring Services Science, 82, pp. 173-188. doi:https://doi.org/10.1007/978-3-642-21547-6_14

Leone, R., \& Guerra, N. (2011). Pequenas e Médias Empresas: contribuições para a discussão sobre por que e como medir o seu tamanho. RAUnP, 4(1), 67-83. https://doi.org/10.21714/raunp.v4i1.194.

Li, J., Strange, R., Ning, L., \& Sutherland, D. (2016). Outward foreign direct investment and domestic innovation performance: evidence from China. International Business Review, 25. doi:1.010-1.019, https://doi.org/10.1016/j.ibusrev.2016.01.008

Lindegaard, S. (2010). The open innovation revolution: essentials, roadblocks, and leadership skills. United States of America: John Wiley \& Sons.

Lopes, P., Santos, S., Silva, V., \& Martins, G. (2018). Fatores determinantes da inovação gerencial. Revista Eletrônica Gestão \& Sociedade, 12(33), 2541-2563. doi:1 0.21171/g e s. v 12i33.2486

Lotka, A. (June de 1926). The frequency distribution of scientific productivity. Journal of the Washington Academy of Sciences, 16, pp. 317-323.

Luft, J., \& Shields, M. (2003). Mapping management accounting: graphics and guidelines for theory-consistent empirical research. Accounting, Organizations and Society, 28, 169-249. https://doi.org/10.1016/S0361-3682(02)00026-0.

Mambrini, A., Cintho, S., Dattein, E., Medina, J., \& Maccari, E. (2011). Cultura inovadora na pequena e média empresa. Revista de Gestão e Projetos-GeP, 2(1), 26-51. https://doi.org/10.5585/gep.v2i1.34. 
Martins, J., Leone, R., \& Guerra, N. (2016). Proposta de método para classificação do porte das empresas. 6(1), 139-155. Mbugua, J., Mbugua, S., Wangoi, M., Ogada, J., \& Kariuki, J. (2013). Factors affecting the growth of micro and small enterprises: A case of tailoring and dressmaking enterprises in Eldoret. International Journal of Business and Social Science, 4, 15.

McDermott, C., \& Prajogo, D. (2012). Service innovation and performance in SMEs. International Journal of Operations \& Production Management, 32, 216-237. https://doi.org/10.1108/01443571211208632.

Meressa, H. (2020). Growth of micro and small scale enterprises and its driving factors: empirical evidence from entrepreneurs in emerging region of Ethiopia. Journal of Innovation and Entrepreneurship, 9(1). https://doi.org/10.1186/s13731-020-00121-9.

Mompo, R., \& Redoli, J. (2009). Innovation strategies for small and medium-sized enterprises. Innovation, 9(1), 57-59.

Mugnaini, R., Carvalho, T., \& Campanatti-Ortiz, H. (2006). Indicadores de produção científica: uma discussão conceitual. Comunicação \& Produção Científica.

Nada, N., \& Ali, Z. (2015). Service value creation capability model to assess the service innovation capability in SMEs. Procedia CIRP, 30, 390-395. https://doi.org/10.1016/j.procir.2015.02.218.

Nang, R., Monahan, F., Diehl, G., \& French, D. (2015). A qualitative content analysis of global health engagements in Peacekeeping and Stability Operations Institute's stability operations lessons learned and information management system. Military Medicine, 180, 409-418. https://doi.org/10.7205/MILMED-D-14-00387.

Oke, A. (2007). Innovation types and innovation management practices in service companies. International Journal of Operations \& Production Management, 27(6), 564-587. https://doi.org/10.1108/01443570710750268.

Okoli, C., \& Schabram, K. (2010). A guide to conducting a systematic literature review of information systems research. Working Papers on Information Systems.

Oura, M., Zilber, S., \& Lopes, E. (2016). Innovation capacity, international experience and export performance of SMEs in Brazil. International Business Review, 25, 921-932. https://doi.org/10.1016/.ibusrev.2015.12.002.

Pikkemaat, B., \& Zehrer, A. (2016). Service innovation, renewal, and adoption/rejection in dynamic global contexts. Innovation and service experiences in small tourism family firms, 10(4), 343-360.

Porto, G. (2013). Gestão da Inovação e Empreendedorismo (1 ed.). São Paulo: Campus.

Prajogo, D., \& McDermott, C. (2014). Antecedents of S ervice I nnovation in SMEs: C omparing the Effects of External and Internal Factors. Journal of Small Business Management, 52, 521-540. https://doi.org/10.1111/jsbm.12047.

Prell, C. (2012). Social network analysis: History, theory and methodology. Sage.

Quadros, R., Furtado, A., Bernardes, R., \& Franco, E. (2001). Technological innovation in Brazilian industry: an assessment based on the São Paulo innovation survey. Technological Forecasting and Social Change, 67(2-3), 203-219.

Roach, D., Ryman, J., \& Makani, J. (2016). Effectuation, innovation and performance in SMEs: an empirical study. European Journal of Innovation Management, 19, 214-238. https://doi.org/10.1108/EJIM-12-2014-0119.

Saetta, S., Tiacci, L., \& Cagnazzo, L. (2013). The innovative model of the virtual development office for collaborative networked enterprises: the GPT network case study. International Journal of Computer Integrated Manufacturing, 26, 41-54. https:// doi.org/10.1080/0951192X.2012.681909.

Schumpeter, J. (1934). The Theory of Economic Development: an inquiry into profits, capital, credit, interest and the business cycle. Harvard University Press.

Schumpeter, J. (1961). Capitalism, socialism and democracy. New York: Harper and Brothers.

Sereia, V., Stal, S., \& Câmara, M. (2015). Fatores determinantes da inovação nas empresas agroindustriais de carne. Nova Economia, 25(3), 647-672.

SJR. (17 de December de 2019). Scimago Journal Ranking. Acesso em 2018, disponível em Scimagoj: https:/www.scimagojr.com/

Slack, N., Brandon-Jones, A., \& Jhonston, R. (2015). Administração da Produção (4 ed.). São Paulo: Atlas.

Small, H. (1973). Co-citation in the scientific literature: a new measure of the relationship between two documents. Journal of the American Society for Information Science, 24(4), 265-269.

Staley, E., \& Morse, R. (1958). Small industry development. research program on small industry development (Vol. 1). Menlo Park, Califórnia: Stanford Research Institute.

Suh, Y., \& Kim, M. (2012). Effects of SME collaboration on R\&D in the service sector in open innovation. Innovation, 14, 349362. https://doi.org/10.5172/impp.2012.14.3.349.

Thakur, R., \& Hale, D. (2013). Service innovation: a comparative study of US and Indian service firms. Journal of Business Research, 66(8), 1108-1123. https://doi.org/10.1016/j.jbusres.2012.03.007.

Tidd, J. (2001). Innovation management in context: environment, organization and performance. International Journal of Management Reviews, 3(3), 169-183.

Tiid, J., \& Hull, F. (2005). Service innovation: organizational responses technological opportunities e Market Imperatives. Imperial College Press.

Tranfield, D., Denyer, D., \& Smart, P. (2003). Towards a methodology for developing evidence-informed management knowledge by means of systematic review. British Journal of Management, 14(3), 207-222.

Vanz, S., \& Stumpf, I. (2010). Scientific collaboration: theoretical and conceptual review. Perspectivas em Ciência da Informação, 15, 42-55. https://doi.org/10.1590/S1413-99362010000200004.

Vargo, S., \& Lusch, R. (2008). Service-dominant logic: continuing the evolution. Journal of the Academy of Marketing Science, 36(1), 1-10. https://doi.org/10.1007/s11747-007-0069-6.

Vinkler, P. (2010). Indicators are the essence of scientometrics and bibliometrics. Scientometrics, 85, 861-866.

Wolff, J., \& Pett, T. (2006). Small-firm performance: modeling the role of product and process improvements. Journal of Small Business Management, 44(2), 268-284. https://doi.org/10.1111/j.1540-627X.2006.00167.X.

Zipf, G. (1949). Human behavior and the principle of least effort. Cambridge, MA: Addison-Wesley Press.

Zupic, I., \& Čater, T. (2015). Bibliometric methods in management and organization. Organizational Research Methods, 18(3), 429-472. https://doi.org/10.1177/1094428114562629.

\section{Publisher's Note}

Springer Nature remains neutral with regard to jurisdictional claims in published maps and institutional affiliations. 